\title{
Achieving Nepal's sustainable development goals (SDGs) by effective compliance of corporate governance
}

\section{Authors}

Anish B.K.: Envisions creating opportunities by accepting challenges and providing with professional touch for transformation. adriot12345@gmail.com

Anish Mahato: an aspiring professional for organization development and change management.

Sajat Thapa: aims to foster organizational development and growth via personal branding.

Ashish Rai: passionate in learning about business environment and creating effective responses for sustainable institutional development and growth.

Niranjan Devkota:

Coordinator-Quest

Research Management Cell

\section{Key Words}

Corporate governance, corporate performance, sustainable development, sustainable development goals; transparency.

\begin{abstract}
Background: it has been almost two that sustainable development has been a global agenda in a form or other. Nepal's efforts to successful execution of millennium development goals (MDGs) also opened new paradigms for the enactment of sustainable development goals (SDGs) planned for 2016-2030. The MDGs based on millennium declaration in the year 2000 by the United Nations (UN) has set foundation for the SDGs 2016-203O.
\end{abstract}

Objectives: The primary purpose of this discourse was to establish the relationship between effective compliance of corporate governance and Nepal's potential for the attainment of SDGs 2016-203O.

Methods: Fully based on desk review performed in a qualitative setting of inquiry.

Results: There is positive relationship between effective compliance of corporate governance (CG) and potential for the attainment of SDGs 20162030 in changing context of Nepal. Further, this paper highlights the general national scenarios, issues, challenges and ways forward in governing sustainable corporate development in Nepal to contribute the nation in its mission to attainment of sustainable development goals 2016-2030.

Conclusions: Effective compliance of corporate governance serves as an instrumental pre-requisite for enhancing national potential to achieve $\mathrm{Ne}$ pal's national shared goals on SDG.

Implications: Nepal needs immediate goals diffusion with appropriate resources allocation for each participant of sustainable development.

Paper type: Review paper 


\section{Introduction}

The principles of corporate governance (CG) have been well-documented in various literature as one of the means of corporate compliance. CG is broader than institutions and means of binding between people, organization and state (Ali, 2015). Further, this scholar has explained that CG provides the mechanisms through which collaboration can be generated across sectors and also some of the fundamental obstacles to sustainable development including exclusion and inequality can be addressed by means of effective CG compliance. There are also a few, but strong cases of corporate failure as a result of lapses in corporate governance. For example, the demise of large corporations such as Enron, Xerox, Tyco and WorldCom in the early 2000 s may be taken as the cases of organizational failure resulted due to failure of maintaining corporate governance (Quang, Kim \& Yi, 2014). Further, Aras and Crowther (2008) have defined that since corporate governance can be highly influential for firm performance, firms must know what the corporate governance principles are and how it will improve strategy to apply these principles. In practice there are four principles of good corporate governance, which are transparency, accountability, responsibility and fairness. Similarly, King (2002) has comprehensively defined the term transparency as a means of ease with which an outsider is able to make meaningful analyses of a institution's actions, its economic fundamentals and non-financial aspects related to a specific institution whereas individuals or groups in an institution, who make decisions and take actions on specific issues, need to be accountable for their decisions and actions is accountability. Similarly, with regard to management, responsibility pertains to behavior that allows for corrective action and for penalizing mismanagement Responsible management would, when necessary, put in place what it would take to set the company on the right path and systematic discussions and review of the operations with multiple stakeholders in numerous focus group discussions would allow for visible documentation of any existing issues or concerns is fairness.

Aras and Crowther (2008) have stated that good governance will address the issue of sustainability, social aspect of sustainability, environmental aspect of sustainability, organizational cultural aspect of sustainability and financial aspect of sustainability. However, Quang, Kim and Yi (2014) have identified that rules and regulation will only function like the guiding principles rather a healthy organizational culture inside the organization should be promoted for the good corporate governance practice. Rules and regulations on corporate governance were enacted in those firms where the activities of the firm are hampering the life of people to enhance their corporate government mechanism as the priority of financial revolution, increase of public confidence, enhancement of corporate governance, and assurance of firm development. Due to globalization and liberalization of the world trade and commerce the firms are getting connected to each other, people are communicating and sharing their knowledge which has given birth to intense competition between the countries, firms and individuals around the world. The world has shrieked into single economy, having said that the international policies, rules and procedures have been developed to control the practices of each involved countries, firms and other involved parties. 
Further, Janggu, Darus, Zain and Sawani (2014) have examined that each organization may carry the different philosophy of corporate governance according to its size, area of operation, location of the firm and so on. According to these scholars, the collapse of big entities accounts various accounting scandals implicitly which took place inside those corporations due to lack of efficient mechanisms on corporate governance. Further, it has been added that such a crisis in CG results a wave of regulations on corporate governance to aid in preventing similar problems occurring in the future. Also, they stated that those regulations focused on improving the CG environment, strict application of principles of CG, implementing guidelines on the independence of the board of directors and audit committees of firms. Different national and international policies have been developed and adopted to protect the right of people inside and outside the organization (Okaro, Ofoegbu \& Okafor, 2018). These scholars have added that board size, professionalism and board designation had significant impact on sustainability disclosure and board independence and board ownership were not significant in motivating sustainability disclosure. They concluded that it is crucial that board characteristics especially board size, board professionalism and board designation be taken into consideration to improve sustainability performance in turn will improve the organizations' social role.

Here stand as Global goals for growth, prosperity and development. The private sector is the most dynamic and economically efficient sector in the case of Nepalese economy. And this sector has given the major contribution in achieving the SDGs goal of Nepal (National Planning Commission [NPC], 2015). Liberal economic policies established by Nepal's government in the early 1990 os provided a significant growth opportunity for the country's private sector. Many private enterprises have developed and become large companies that follow models of economic groups. In practice, however, private economic groups are facing many issues, which originate from week corporate governance. Main owners of large private enterprises commonly have cross-ownership in many other companies and financial institutions, and decision making of those enterprises is mostly made by those cross-ownership shareholders.

In this work entitled, 'attainment of sustainable development goals (SDGs) of Nepal through effective compliance of corporate governance (CG)', the present researchers have attempted to examine the contribution of effective compliance of CG in attaining SDGs of Nepal for 2016-2030. Thus, the present work was guided by the purpose to examine the contribution of effective corporate governance on attaining the SDGs. More specifically, the present study has attempted to --

a. identify the good corporate governance practices,

b. assess the linkage between corporate governance and sustainable development,

c. examine the issues involved in attaining UN-SDGs, and

d. determine the current state of sustainable corporate development in Nepal.

While assessing the linkage of effective corporate governance practices, issues, current scenarios in the process of attaining Nepal's national goals on sustainable development, it allows us to understand and clarify the picture of two major concepts -- corporate governance practices and SDGs goals. To ensure a good corporate governance in Nepal requires a joint 
effort of the investors (promoters) who need to be more transparent, responsible and socially accountable; the shareholders who must actively participate in their corporate affairs to help prevent any fraudulent and insider practices and; the regulatory authority that should effectively enforce rules and regulations in order to protect the rights of all stakeholders and create favorable environment to enhance good corporate governance culture. Liberal economic policies established by Nepal's government in the early 1990 s provided a significant growth opportunity for the country's private sector. Numerous studies have indicated that the prolonged political instability has weakened the country's governance and which has been a critical constraint on private sector development. So, the question arises: Is the political instability and loophole in government policies the major constraint for sustainable corporate development and attaining the SDGs? The present study team also crafted a set of research questions to accomplish the overall work in a systematically guided manner.

a. What are the practices of good corporate governance?

b. Is corporate governance practice of Nepalese private firms supportive to SDGs of Nepal?

c. How effective corporate governance does help to attain the SDGs of Nepal?

d. Should governance be treated as a stand-alone SDG or integrated into the other issues?

e. What is the current scenario of sustainable corporate development in Nepal?

This article does not provide an in-depth analysis of various factors and forces. Instead, provides synoptic view of various issues and problems related to good corporate governance practices and its contributions in attaining SDGs of Nepal. There is no doubt that the results of this work would not only facilitate the scholars and experts of politics and civil society activism but it would be also a massive contribution for the students, corporates, and policymakers in the field of development studies and policy formulation and implementation for attaining the SDGs. The study holds the following limitations:

a. This study mainly relies on the review of secondary sources, which are collected from different authorized sites from internet. But this study was not able to review all those literatures in detail.

b. There are abundant reports published by national and international agencies so there are slight differences in data provided by those reports.

For the purpose of making it simple to understand among the readers, the present study team also established a set of operational definitions, which are as follows:

Corporate governance: Corporate governance can be defined as the quality, transparency and dependability of the relationships between the shareholders, board of directors, management, and employees. Further, it refers to the authority and responsibility of each in delivering sustainable value to all the stakeholders in order to attract financial and human capital to the corporation and to ensure sustainability of value creation; the governance mechanisms should ensure to gain the trust of all stakeholders (Aras \& Crowther, 2008). 
Corporate performance: Likewise, to achieve Corporate Governance and Sustainability relating to measurement of corporate performance even the Corporate Sustainability Reporting gains a great importance (Kocmanová, Hřebíček \& Dočekalová, 2011). Further, Corporate Governance and on economic, environmental and social issues relating to measurement of corporate performance that can lead even to permanent success.

Transparency: Transparency is the ease with which an outsider is able to make meaningful analysis of a company's actions, its economic fundamentals and the non-financial aspects pertinent to that business (Ali, 2015). Further, he explains that it is a measure of how good management is at making necessary information available in a candid, accurate and timely manner - not only the audit data but also general reports and press releases. It reflects whether or not investors obtain a true picture of what is happening inside the company.

Sustainable development: Okaro, Ofoegbu and Okafor (2018) have argued that sustainability is a strategy of the process of sustainable development and it acquires special importance when the process helps people progress toward sustainability or may be, on the contrary, dissuade them from engaging in the process. Further, these scholars have also explained that sustainability is the ability to sustain the quality of life or the ability to maintain quality, which means that each generation has a responsibility for the quality of life and needs to continuously improve it. Sustainability in connection with the business environment has become part of the general awareness as a result of environmental approaches implemented in companies.

This work was accomplished as a purely exploratory discourse run on qualitative paradigm of exploration from existing multiple sources of information including desk reviews of research reports, journal articles, policy guidelines and books related to SDGs planning and policy interventions and CG practices in developing context of Nepal. In addition, expert opinions were also solicited to make effective choice of relevant contents of coverage required to accomplish this task.

\section{Review of literature}

Since the overall work has been accomplished by performing review of selected literature, adequate emphasis was placed on choice of related conceptual perspectives, principles and practices as well as effective models of planned approach to attainment of defined goals for sustainable development, with specific reference to Nepal. Subsequent sub-sections provide with detailed accounts of review of literature performed.

\section{Concept of corporate governance (CG)}

CG is a broad term which involves the methods, structure and the processes of a company in which the business and affairs of the company is managed and directed (Aras \& Crowther, 2008). According to these scholars, CG describes the processes, customs, policies, laws and institutions that direct the organizations and corporations in the way they act, administer and control their operations. Further, its major focus is the goal of the organization and helps to manage the relationship among the stakeholders including the board of directors and the 
shareholders which also deals with the accountability of the individuals. Good corporate governance is essential for the striking investment environment which is needed by competitive companies to gain strong position in efficient financial markets and also facilitates the success for entrepreneurship (Jensen \& Meckling, 1976; Berle \& Means, 1932; as cited in Khan, 2011).

At this outset, Khan (2011) has defined CG as allocation of ownership, capital structure, managerial incentive schemes, takeovers, board of directors, pressure from institutional investors, product market competition, labor market competition, organizational structure, etc. that affects the process of good corporate governance. According to this scholar, corporate governance as a part of business philosophy, refers to the private and public institutions that include laws, regulations and the business practices which govern the relationship between the corporate managers and the various other stakeholders.

Corporate governance can be seen from two perspectives Quang, Kim and Yi (2014) have said that external and internal corporate governance. External corporate governance deals with external stakeholders such as creditors, suppliers, and many others outside the organization, while internal corporate governance focuses on the board of director and the interests of shareholders.

Organization for Economic Cooperation and Development ([OECD], 1999) has defined the six principle of Corporate Governance which specifies the distribution of rights and responsibilities among different participants in the corporation, such as the board, managers, shareholders and other stakeholders and also spells out the rules and procedures for making decisions on corporate affairs. Further, they explain that corporate governance provides the structure through which the company objectives are set, and the means of attaining those objectives and monitoring performance. Where, OECD core principle are:

a. Ensuring the basis for an effective corporate governance framework

b. Basic rights of shareholders and key ownership functions

c. Equitable treatment of shareholder

d. Role of stakeholders in corporate governance

e. Disclosure and transparency

f. Board responsibilities

The OECD principles serve as the framework for corporate governance. The legal and regulatory requirements that affect corporate governance practices should be consistent with the rule of law, transparent and enforceable. The division of responsibilities among different authorities should be clearly articulated and designed to serve the public interest. Supervisory, regulatory and enforcement authorities should have the authority, integrity and resources to fulfil their duties in a professional and objective manner. The corporate governance framework should protect and facilitate the exercise of shareholders' rights ensuring equitable treatment of them.

Accurate disclosure of financial situation, performance, governance of the company, company objectives, major share ownership, remuneration policy, foreseeable risk factors, governance structure and policies are required. Company's strategic direction and monitoring of the 
management by board and its accountability have to be disclosed. Further, Homayoun and Abdul Rehman (2010) have presented with a model of corporate governance by outlining its key elements and processes which explain the power division and build up mechanism for achieving shareholder accountability and board management.

Figure 2: Corporate governance model

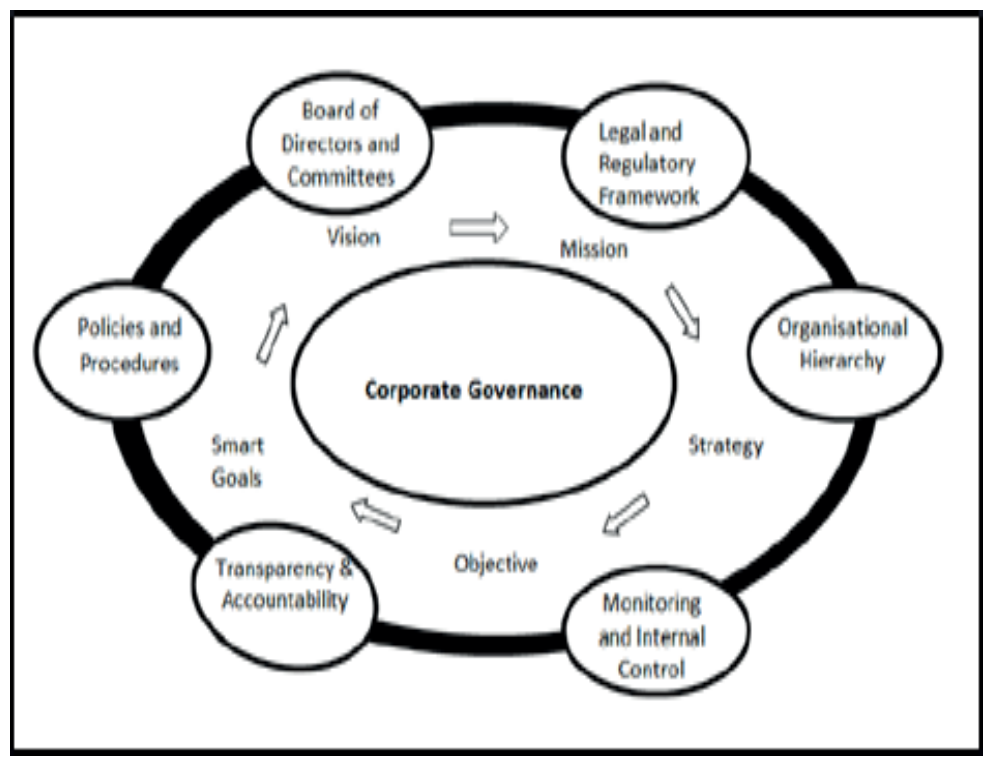

Source: Asogwa. (2016), CG in Nigerian Banks: a Theoretical Review

Likewise, according to Dine and Koutsias (2013), a key aspect of corporate governance is concerned with ensuring the flow of external capital to companies both in the form of equity and credit. Further, it is also concerned with finding ways to encourage the various stakeholders in the firm to undertake economically optimal levels of investment in firm-specific human and physical capital. According to this scholar the ultimate success of a corporation is the result of teamwork that embodies contributions from a range of different resource providers including investors, employees, creditors, and suppliers. It is, therefore, in the longterm interest of corporations to foster wealth-creating cooperation among stakeholders. An effective system of corporate governance in terms of the institutional environment, providing a reliable guarantee of property rights (including their specification, the protection of legitimate owners, as well as a remedy during transmission) and the conditions for fair competition, allows you to generate innovation which is essential for ensuring the sustainability of economic growth during the second economic revolution (Kelton \& Yang, 2008).

Soewarno (2018) has stated that the significance of good governance involves processes for making and implementing decisions. It's not about making 'correct' decisions, but about the best possible process for making those decisions. It has its own area of significance in various disciplines like political science, administrative Sciences and development studies. Good governance is important for several benefits. First and foremost, quality of governance 
has to be judged by the performance of the relevant institution because size and nature of the firm differs the activity of good governance practices. Therefore, the goal of the institution has to be clearly defined as a matter of major priority. Similarly Ali (2015) has recalled that the next important fact is defining decision rights and processes, as well as establishing a feedback loop to verify and control performance. Governance is how the firm is ruled and operated; it is how the authority, responsibility, and controls are required in the institution. The system of corporate governance provides a balance of rigidity requirements for managers from other stakeholders while maintaining a sufficient degree of flexibility in decision-making for the initiation and continuation of profitable projects, suggesting a significant level of risk and the possibility of failure of some projects and their timely termination. At the same time, Asogwa (2016) has claimed that an effective system of corporate governance in terms of generating innovation is hardly possible without a sustainable protection of property rights, ensure a sufficient level of transparency, competition, and the depth of the financial infrastructure economics noted that there is a direct relationship between the degree of protection of the rights of investors, shareholders and the scale of the development of the capital market. Governance is relevant to all types involving institution, small or large; for profit or not; extending from a single family all the way to global institutions that have an impact on the daily lives of the people. Hence, good governance is relevant for quality of life now and for its sustainability in the future. In the absence of democracy, peace and good governance, sustainable socio-economic progress is not possible.

\section{Concept of Sustainable Development}

The concept of sustainability is often described as an 'essentially contested concept', which means that it is a concept that is not set in stone but are highly dependent on the specific context and perspective on the matter. Strange and Bayley (2008) have recalled that in the early 21st century the term sustainable development started to gain wide acceptance. The concept of sustainability made its way around the world into everyday language and into community activities. The result of UN-convened commission created to propose "a global agenda for change" in the concept and practices of development. The agenda of the UN started getting popular around the world when the world had gone through lots of problems related to economic crisis and world environmental disasters. For international co-operation and co-ordination, the sole objective of the international agenda is focused to meet humanity's goals and aspirations.

Those scholars have further stated that the agenda of sustainability is to draw the world's attention on several issues concerned with accelerating deterioration of the human environment and natural resources and the consequences of that deterioration for economic and social development. Sustainable development means the use and exploitation of today's resource in such a manner that these resources will be available for use of future generations. It is about integration of national and international policies and practices that benefits the widest possible range of sectors, across borders and even between generations.

The Sustainability Accounting Standards Board (SASB) has identified sustainability topics from a set of 26 broadly relevant sustainability issues organized under these five 
sustainability dimensions. They are -- environment, social capital, human capital, business model and innovation; leadership and governance as presented in figure 3 below.

Figure 3: Foundations of sustainability development

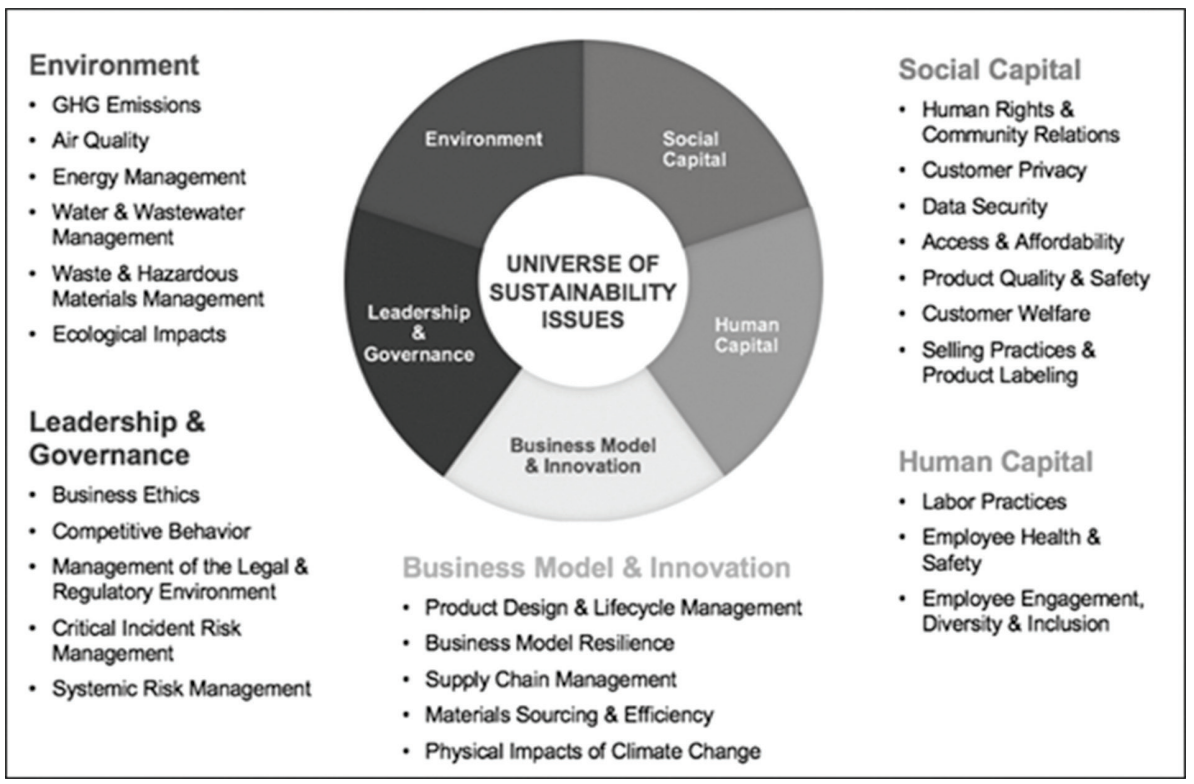

Source: Sustainability Accounting Standards Board (SASB). (2011)

Sustainability accounting reflects the management of a corporation's environmental and social impacts arising from production of goods and services, as well as its management of the environmental and social capitals necessary to create long-term value. It also includes the impacts that sustainability challenges have on innovation, business models, and corporate governance and vice versa. Therefore, SASB's sustainability topics are organized under five broad sustainability dimensions:

Environment: This dimension includes environmental impacts, either through the use of nonrenewable, natural resources as inputs to the factors of production or through harmful releases into the environment that may result in impacts to the company's financial condition or operating performance.

Social capital: This dimension relates to the expectation that a business will contribute to society in return for a social license to operate. It addresses the management of relationships with key outside parties, such as customers, local communities, the public, and the government. It includes issues related to human rights, protection of vulnerable groups, local economic development, access to and quality of products and services, affordability, responsible business practices in marketing, and customer privacy.

Human capital: This dimension addresses the management of a company's human resources (employees and individual contractors) as key assets to delivering long-term value. It includes issues that affect the productivity of employees, management of labor relations, and 
management of the health and safety of employees and the ability to create a safety culture.

Business model and innovation: This dimension addresses the integration of environmental, human, and social issues in a company's value-creation process, including resource recovery and other innovations in the production process; as well as in product innovation, including efficiency and responsibility in the design, use phase, and disposal of products.

Leadership and Governance: This dimension involves the management of issues that are inherent to the business model or common practice in the industry and that are in potential conflict with the interest of broader stakeholder groups, and therefore create a potential liability or a limitation or removal of a license to operate. This includes regulatory compliance, risk management, safety management, supply-chain and materials sourcing, conflicts of interest, anticompetitive behavior, and corruption and bribery.

The governments face the complex challenge of finding the right balance between the competing demands on natural and social resources, without sacrificing economic progress. The issue of sustainability is not only the matter of concern for government rather it is the matter of concern authority that could be either the divisions and departments of government, communities and even households. The concern bodies handle the issues that come under their domain. Sustainability doesn't only mean the economic development rather it includes the wide spectrum of social and environmental aspects, political, technological and socio-economic aspects of any action that are interconnected. And if we talk from the view point of private sector then focusing only on profit margins, for example, has historically led to social and environmental damages that cost society in the long run. Therefore, it doesn't comply with the definition of sustainability and growth.

Likewise, sustainability is not just environmentalism. It is also connected with the concerns for social equity and economic development. In the name of attaining sustainable development goal, so many individuals, groups and communities are working towards the achieving of this goal. Some of the individuals and organizations demonstrate this value in their policies, everyday activities and behaviors (United Nations Organization [UNO], 1986).

\section{Linkage between corporate governance and sustainable de- velopment}

Strange and Bayley (2008) have indicated that the relationship between corporate governance and sustainable development came into life when both of these terms were accepted for global cooperation, based mainly on joint coordination of strategies and adopting of the best decisions. The foundation of sustainability and sustainable development stand on three major pillars that comprise the economic, social and environmental pillars. The economic pillar is based on the necessary retaining of ordinary capital with all the business activities performed, and use of only the generated profit. The social pillar involves individuals as well as the community. The environmental pillar focuses on environmental protection concerned with improvement and prevention of excessive use of natural resources. Further, Stojanovic, Ateljevic and Stevic (2016) have examined that good governance is the tool for the Sustainable Development. The growing concern on the different environmental degradation, disap- 
pointment with development efforts to reduce the poverty and inequality on a global scale with the economic and socio-political instability has shifted the focus from the economic growth model to sustainable development model. On the other side of the coin, corporate governance is a system through which companies are managed and controlled. It is understood as the key element in the effort to reach economic efficiency by earning the investors' trust. It consists of wide range of issues arising from the relationships between the corporate management, the administrative authorities, shareholders and the other stakeholders.

At present the company's major focus is on sustainable development as well as sustainability. It means for companies, sustainability demand for changes to the corporate culture as well as society. In addition, good governance promotes freedom from violence, fear and crime, and peaceful and secure societies that provide the stability needed for development investments to be sustained. Sustainability has three important dimensions for all companies as discussed in the previous section which is concerned with economic growth, social responsibility and responsibility for the environment. The social and environmental responsibility is inseparable from economic growth. Profitability and growth create jobs and wealth where companies have to continue to provide products and services that people are demanding.

There are some common points where the sustainable development and good corporate governance gives the similar meaning with the common agendas, as mentioned below (Kocmanová, Hřebíček \& Dočekalová, 2011):

a. Promoting ethical responsibility and sound corporate governance practices,

b. Providing a safe working environment for employees and concerned for self-development are enhanced,

c. Promoting cultural diversity and equity in the workplace,

d. Minimizing adverse environmental impacts, and

e. Providing opportunities for social and economic development within the communities where firm operate.

Therefore, for the sustainable development of the corporate sector the principles of good corporate governance play the special role for long term survival and growth of the company. The three major pillars of sustainability are at the heart of the corporate and business strategies; they are part and parcel of daily operations, stimulate work for success, work as an indicator of threat and risk assessment and show the direction towards survival and growth. This become part of the voluntary corporate reporting on the assessment of links between the environmental and economic assessment of performance, the social assessment of performance and the relation to Corporate Governance. When we are talking about the three major pillars of sustainability then it is important to discuss these factors from both national and international point of view because in today's globalized world the economic trend that starts in one country affect many others. The national economies are affected by the internationalization of production and international trade. Resource management, pollution control and climate phenomena are all issues that by their nature reach beyond geographical borders, making the challenges of sustainability a priority shared by countries and communities all around. 
Supporting the sustainable development goals by Nestlé: Nestle have recently won 'Best Corporate Governance in Food and Beverage Sector' award in 2018. Contribution to Sustainable Development Goals (SDGs) by the Nestle was observed in the report of "Nestlé in society Creating Shared Value and meeting our commitments 2017". Maximum contribution of the organization towards the goal 17 that they have contribute to the implementation and revitalizing the global partnership for sustainable development. Similarly, they have also contributed to all the 17 goals through the development of the Individuals, family, communities and planet which all because of good corporate governance practices.

\section{UN-SDG and Nepal}

Since last two decades Sustainable Development has been a global agenda and Nepal, as a member of the UN, is a part of this global initiative. The Millennium Development Goals based on Millennium Declaration in the year 2000 by the United Nations has set foundation for Sustainable Development Goals (SDGs) to be achieved by 2030. The UN Conference on Sustainable Development held in Rio de Janeiro in June 2012, and UN General Assembly (UNGA) held in September 2014 prepared solid foundation for SDGs and finally agreed in the UNGA held in September 2015 (National Planning Commission [NPC], 2015).

Thereafter, according to NPC (2015), United Nation's sustainable development agenda become Nepal's socio-economic development goals for the nation's welfare and prosperity. Nepal's successful implementation of the millennium development goals (MDGs) opened new path for the implementation of SDGs planned for 2016-2030. With a hope of achieving national prosperity and welfare, Nepal has taken strong steps in operationalizing the SDGs at all levels national, regional and local. Even before the UN global agenda, the government of Nepal was already in the process of preparing a national agenda since long back to eradicate the poverty, increase the literacy of the country and other agenda on sole purpose for welfare of the nation.

As a matter of fact, Nepal is a least developed country (LDC) characterized by slow economic growth, underdevelopment of socioeconomic aspects and a low level of human development, where millions of people are living under the poverty line earning less than $\$ 1$ per day. It is emerging from a politically and socially fragile post-conflict situation, structurally generated poverty and inequality, and deeply entrenched forms of social exclusion. Over the last decade the economic growth of the country (National Planning commission [NPC], 2015) has averaged 4 percent and the target is set to $6 \%$ annual growth rate. There are large disparities in the rates of poverty by gender, social group and geographical area. However, a major chunk of its population lives below the poverty line.

Accordingly, NPC (2015) has indicated Nepal already being successful in reducing absolute poverty and is on a right track to halve the proportion of people suffering from hunger. In the education sector, the net enrolment rate in primary education reached 96.2 percent in 2015, and 86.8 percent of students who start in grade one now reaches grade five. Likewise, Substantial progress has been made in child health with the Millennium Development Goal targets on infant mortality and under-five mortality already being met and rates of malnutrition substantially decreased. Water supplies to large group have increased from 46 percent 
in 1990 to 83.6 percent in 2014, thus achieving the target set by national and Millennium Development Goal. Sanitation facility rose from 6 percent in 1990 to 70.3 percent in 2014. Drastic progress has been made on attaining the SDGs which is impressive despite the long political instability with prolonged peace process.

The current status of Nepal on SDGs targets has been discussed below with various supporting facts (NPC, 2015):

$S D G$ 1: The first goal of SDGs proposes ending poverty and bringing it down to level where the country is able to ensure the high human development and per capita income. Using the international benchmark for extreme poverty of an income of US\$ 1.25 per day, less than 25 percent of the population are below the poverty line. The poverty gap ratio has narrowed to 5.6 percent, while per capita GNI stands at US\$ 772 in 2015. Poverty is targeted to decline from 23.8 percent to 5 percent by 2030.And most possible to bring down the poverty by more than 50 percent to all with in all age group living below the poverty line. Nepal government also has plans on bringing the poor under the social security and implement the social security practices at national level. To ensure the poor and backward population to be able to face and fight the natural and unwanted calamities and develop the strategies where they can face them and create a strategy that will deduct the negative effects on them. It also plans on investing more and more on the program that are related to poverty alleviation and promote it at national, regional and at international levels and forums.

$S D G$ 2: The second goal proposes ending hunger, achieving food security, improving nutrition and promoting sustainable agriculture. The data shows that 30 percent of children aged 6-59 months are underweight. The target is to reduce the prevalence of stunting in children under five years, of underweight children (aged 6-59 months), and anemia among women of reproductive age and children to less than one percent. The plans are also to end the hunger and ensure that all the citizen of the country have enough food for the whole year by 2030. The plan also has ideas to increase the agriculture practices and create maximum investment opportunities and markets and ensure the growth rate to be doubled. It also focuses on land management policy for ensuring the quality, ownerships and development of the agriculture uses as well as improve the different factors to improve the climates and possible threats from the climate changes.

$S D G$ 3: The third goal ensures healthy lives and promotes well-being for all people of all ages. The progress in the health sector has been encouraging and it is in a position to meet the goal of healthy citizens. The targets for 2030 are to reduce maternal mortality ratio (MMR) to less than 70 per 100,000 live births, to reduce preventable deaths to less than 1 percent of new born and children. Similarly, the next target is to eliminate the prevalence of the human immunodeficiency virus (HIV), TB, malaria, other tropical diseases and water borne diseases. By 2030 it plans to reduce the deaths from non-communicable to one third. It also plans on having reach of sex and maternity education to everyone. To aware and eliminate the danger of different health problems to the people.

$S D G$ 4: The fourth goal aspires to ensure inclusive and equitable quality education and promote lifelong learning opportunities for all. The country has made good progress in primary 
education with the NER now standing at 96.2 percent and the literacy rate of 15-24-year old at 88.6 percent. Some of the proposed targets for 2030 include almost 100 percent enrolment and the completion of primary education. And 95 percent of students being enrolled in grade one to reach grade eight, and 90 percent of children attending pre-primary education. Equality and equity in education system for all the genders at every level of education. To increase and develop the youths that are well skilled and has that entrepreneurial ability to create value for the nation. Making the country 100 percent literate by coming few years.

$S D G$ 5: Fifth goal is about achieving gender equality and empowering all women and girls. Nepal has made substantial progress in ensuring equal access to education for female, with gender parity in primary and secondary level school enrolment. National laws and policies have been enacted to reduce violence against women and girls. For 2030, Nepal has set target to eliminating gender disparity in all levels of education, wage discrimination at similar work, physical and sexual violence, and all harmful practices, and raising the presence of women in the national parliament and public service decision-making positions. The goals also focus on ending every type of gender discrimination and has strong actions for human trafficking, sexual harassments, assaults, and domestic violence and child marriages. To influence and have active participation of woman on any kind of economic, public decision and political decisions.

$S D G$ 6: The sixth goal is focused on the availability and sustainable management of water and sanitation for all. The data shows water supply coverage in Nepal was 83.6 percent in 2014, while sanitation had reached 70.3 percent of the population. Two-thirds of the Nepali population now use latrines and 30 percent of urban households are connected to sewerage systems. The targets set for 2030 include 95 percent of households having access to piped water supplies and improved sanitation, all communities being free of open defecation, and all urban households being connected to a sewerage system.

$S D G$ 7: The seventh goal aspires to access to affordable, reliable, sustainable and modern energy for all. Nearly three-quarters of households use solid fuels as primary source of energy for cooking while more than a quarter use liquid petroleum gas (LPG). Nearly three-quarters of households have access to electricity. The proposed targets for 2030 include 99 percent of households with access to electricity, only 10 percent of households using to firewood for cooking, the generation of at least 10 thousand megawatts of electricity, and decreasing energy intensity by 0.8 percent per annum. To increase the investment on green energies and have reach on the green energies at most.

$S D G$ 8: The next goal aspires for sustained, inclusive and sustainable economic growth, full and productive employment and decent work for all. Nepal is targeted to achieve at least seven percent per annum growth in per capita gross domestic product by 2030. And, agriculture and construction is targeted to achieve 5 and 10 percent growth respectively. As well as increase in the income level of the people and diversify the labor intended market along with the technological changes and implementation. Make policy and easy road for the small and medium scale industries to rise and prosper. It also plans on reducing the significant amount of youths having no trainings and guidance on employment, education and by the 2020. To 
ensure policy and insurance the protection of the lives of Nepali migrants working at foreign lands and develop programs to attract the youths to comeback and work in the country itself. It also has plans that will ensure the reach of people to every possible financial institution and will increase the ability of the financial institutions.

$S D G$ 9: The ninth goal is for resilient infrastructure, inclusive and sustainable industrialization, and innovation. In regard with these goals, about 12,500 km of the country's strategic road network and about 53,000 km of the local road network have been built. The targets for 2030 are to increase road density from the current $0.44 \mathrm{~km} / \mathrm{km} 2$ to $5 \mathrm{~km} / \mathrm{km} 2$, increase access to telecommunications (tele-density) to 100 percent, and raise the share of industry in total output to 25 percent. It has one of the main goal to improve the economic development and have human prosperity for everyone and have sustainable and long term developments. The goal of the SDG is also to provide loans at reasonable rate and encourage the small industries to Prosper and develop. Increase the communication and technology and be able to reach the use of internet to each and every individual with in the country.

$S D G$ 10: Reducing inequality is the tenth equally most important goal. In Nepal, consumption inequality (as measured by the Gini coefficient) 2014 was estimated at 0.33 , and the share of the bottom 40 percent population in total income was about 12 percent. The proposed targets for 2030 are reducing consumption inequality from 0.33 percent to 0.16 percent, increasing the share of national income of the bottom 40 percent of the population from 12 percent to 18 percent, and increasing social, economic, and political empowerment indices to 0.70 . The goals also focus on unbiased practices of laws and rights to every citizen of the country and make the practices sustainable and rightful. Make rightful laws for the wages and salaries and make policy to control the unwanted and corruption as wee ass monitor the national and international organization and bring them with in the law.

$S D G$ 11: The eleventh goal aspires to make cities and human settlements inclusive, safe, resilient and sustainable. It is estimated that 7 percent of Nepal's urban population lives in a quarter settlement and only 30 percent of houses are safe to live in. The targets set for 2030 include reducing poverty, ensure safe houses, and increase the road density to five $\mathrm{km} / \mathrm{km} 2$, making 50 percent of roads safe by following international standards. Sustainable transportation system for all, and make long term attainable urban plans and policies for the human prosperity.it also focuses on conservation and protection of the world heritage and cultural heritage. The goal also has plans on reducing the household wastage and have sustainable waste management programs. And eliminate pollutions from the city and urban areas.

$S D G$ 12: The next goal is concerned with sustainable consumption and production patterns. The data shows only 10 percent of water resources have been used and 12.5 percent of fuels comprise only fossil energy consumption. The targets set for 2030 include fossil fuel consumption to 15 percent of energy consumption and improving the soil fertility from 1 percent in 2014 to 4 percent in 2030. To reduce human food waste per person is also the goals of the SDG and stop the plastic wastages and only use reusable products.

$S D G$ 13: The thirteen goals are concerned with action to climate change and its impacts on the life of the people. In Nepal, the total emission of carbon dioxide (CO2), at 0.10 metric tons 
per capita, is negligible and the consumption of ozone depleting substances (ODS) is only o.88 ODS tons. The targets for 2030 include reducing more than half the emission of $\mathrm{CO} 2$, OD and greenhouse gases from agricultural, transportation, industrial and commercial sectors.

$S D G$ 14: The fourteen goals of SDGs are concerned with conserving and sustainably using the oceans, seas and marine resources for sustainable development which is not quite relevant for Nepal because the country has no access to these resources. But, as mountain resources are so crucial for Nepal's fresh water resources, hydropower, livelihood, agriculture, and adventure tourism and environment protection. Some special targets are set for the conservation of the resources.

$S D G$ 15: The third last goal of SDGs proposes for protecting, restoring and promoting the sustainable use of terrestrial ecosystems, sustainably managing forests and halting biodiversity loss. Nepal's current forest cover includes 39.6 percent of bushes and grassland. Further the protected areas cover 23.2 percent of the country's land area. And the targets for 2030 are to increase forest coverage to 45 percent and protected areas to 25 percent.

$S D G$ 16: The second last goal calls for promoting peaceful and inclusive societies for sustainable development among others. Nepal scores only 3 out of 6 for transparency, accountability and corruption in public life. Nepal is ranked as 124th position in the world corruption list as per the data of 2018. The targets set for 2030 include ending deaths from violent conflict, violence against women and violence against children, and improving the transparency and accountability score to 5 , and the score on the good governance scale to 2 .

$S D G$ 17: Finally, the last goal is all about strengthening the means of implementation and revitalizing the global partnership for sustainable development. This goal is concerned with 19 targets, including adequate finance, technology, institutions, capacity and partnership are vital for achieving the SDGs. These components have a synergetic effect. The current availability of resources indicates that there is a large gap to finance the achievement of the SDGs. Nepal also needs technological support including smart technology for small-scale agro-based entrepreneurs and low carbon emission engineering for its industries. Partnerships are being strengthened with the private sector, cooperatives, civil society, development partners and the international community to meet the large capacity building needs.

Therefore, building on the relative success of the Millennium Development Goals, Nepal is committed to pursuing and achieving the stated Sustainable Development Goals (SDGs) by 2030. While SDGs are an internationally agreed set of common development objectives, these global ambitions are broadly aligned with the social, economic and environmental aspirations that Nepal has set for itself in its new constitution. The SDGs are not just an international milestone, but they represent a set of commitments made by the people of Nepal for shared progress.

\section{Current state of sustainable corporate development in Nepal}

The private sector played crucial role in promoting economic growth, generating jobs, and contributing to the government's revenue. It has both direct and indirect impact in the economic development of the country through policy implementation and assisting government in policy recommendation and formulation. Besides, its corporate social responsibilities and 
role in social security or social protection has greater contribution in achieving the SDGs. Few years back overall penetration of CSR in Nepal was very low due to many corporations unknown or ignorant about the overall concept of CSR and its support to gain SDGs. And only few organizations like Chaudhary, Panchakanya groups and some banks were on limelight doing part in CSR. But in the recent trend and changing times many businesses in Nepal has started to feel the need of CSR in day to day operations which has been a part in accomplishing the sustainable developments goals set by Nepal for sustainability. As a part of CSR NTC has opened is hand for Bagmati river cleanup campaigns and with cooperation with Ministry of Agriculture and Development it has distributed 5500 SIM cards to the farmers. Asian Paints has been prioritizing on the education area and supporting the education of 50 deprived children with the collaboration with women for human rights, single women groups, like wise Bhatbhateni group has CSR policies made in the education field of MBBS where two students who are capable and from the remote areas. This shows that there has been lot of work been done and on process from the private sectors for the development goals and social responsibility. However, the primary responsibility to achieve the SDGs rests with the government. Exercising this responsibility requires support of the private sector to scaleup investment along with developing the capacity of the country's human resources. So, for the proper implementation a large part of investment will have to be financed from domestic resources, and so such funding has to be sustainable (Strange \& Bayley, 2008).

To support the sustainability of the corporate sector, government has bought lots of recent policy changes in industrial rules, regulations and investment policies. The achievement of the SDGs requires good governance at all levels. With the restoration of peace, investor confidence was renewed, which led to increased private investments. There are some issues that have constraint the growth of the private sector held back by low trust, cartels, a fragmented business lobby, and risk-averse business behavior. The private sector since 2001 has been contributing to about 80 percent of the country's gross fixed capital formation (Ministry of Finance, 2018), which is equivalent to about 17 percent of its Gross Domestic Product (GDP). Evidence of improvement such as credit to private sector grew by $22.3 \%$ in FY2018, up from the growth of 18 percent in the preceding year. There is further potential in private sector investment from both domestic and foreign sources in sectors like agriculture, hydropower, and tourism. Nepal's private sector is dominated by small- and medium-scale enterprises, which comprised more than 90 percentage of the total registered businesses and accounted for about 22 percentage of GDP in FY2012. Construction activities have greatly increased and now account for 6 percentage of GDP.

Looking back to the history, the Trade Policy of 1992 was focused on promoting sustainable trade to enhance the national economy by undertaking open and liberal policies, and by allowing wider participation of the private sector. As a result, growth in the service (tertiary sector) has been mainly driven by private sector investment. As per the economic survey by Ministry of Finance (2018), 483.2 MW of hydropower produced by the private sector has been connected to the national grid. Until the FY 2016/17, purchase and sale agreement has been made between private sector power companies and Nepal Electricity Authority for 213 
projects equivalent to 3,395 MW of installation capacity. As per the efforts made by government and private sectors, the total enrolment rate for early childhood development has reached to 84.1 percent.

In this scenario government plays a crucial role by disseminating information concerning present and prospective export markets, flowing of trade information and intensifying the monitoring and evaluation process. The additional support could be ensuring access to justice and security, pro-growth policies, engaging all local stakeholders in formulating and implementing the SDGs, and making public services more accountable and public policies, programs and implementation more transparent and result-oriented. The private sector can play a leading role in shaping the post-conflict socio-economic conditions of a New Nepal.

\section{Methodology and scope of works}

This paper has been prepared purely based on exploratory discourse of learning and the work was mostly confined to desk reviews of reports, journal and books related to SDGs planning and policy interventions and CG practices in the context of Nepal in compliance with national and international practices. Similarly, expert opinion was taken to make a choice on current burning issues and scenarios that are relevant to the study.

Most data for reviewing SDGs progress were taken from the published report of NPC and United Nations Development Program (UNDP). Other sources of information included the annual and periodic reports of the World Bank (WB), Asian Development Bank (ADB), and the International Monetary Fund (IMF).

The overall style of documenting the paper has been a blend of narratives, qualitative discourse and subjective assessment of policy and plan forwarded by the national and international bodies for attaining SDGs. And, it was prepared within the time frame of 2 months.

\section{Key findings and discussions}

Corporate governance and sustainable development are corresponding and respectively occurring events that are equally important for any organizations proper attainment of its ultimate objectives, goals and sustainability. And it has been proved that the Corporate Governance is the tool for sustainability and development. The Corporate Governance and Sustainable Development promotes ethical responsibility and practices respectively. The sustainable development plays a special role in long term survival and growth of the company. Sustainable Development Goals are not able to be obtained by one unit of the sector but it should the joint efforts of both the private organizations, public and the government as well. And for the SDGs to reach it's designed destination the governance and policy made by the government should be environment friendly. As it is seen in the past that lobbying had a great and huge effect in the policy making and only the few organization with the reach to power were benefited, the government should be fair and make policy that are supportive to every possible businesses. And only the private business gain trust on their investment and have no fear on getting out of the businesses. The results has been seen after the NPC policy 2015, as the situation on different level of firms has changed and the CSR are been highly seen from them. 


\section{Conclusions}

Based on the analyses of prevailing national scenario and issues of SDGs and sustainable corporate development, corporate governance has been widely accepted and recognized as one of the key elements in achieving economic performance and growth ensuring increased trust of the stakeholders. Mostly, our observation has identified that the UN-SDGs 201620132 for Nepal are crafted in consistent with the fundamental rights of the citizens as per the new Constitution of Nepal. Also, the SDGs are observed to be determined in line with the country's medium-term roadmap with a long-term vision of transforming nation towards prosperity with equity and social justice. The ambitious SDGs require federal, state and local ownership and commitment with substantially up-scaled resources and capacity to implement them at both the national and international levels.

The study team has also identified limited resources, lack of coordination among development partners, poor capacity to translate SDGs into national programs and insufficient resources to finance as the key impeding issues and challenges facing attainment of Nepal UN-SDGs 2016-2032.

However, Nepal has made a robust progress in reducing absolute poverty despite far from favorable political and economic climate. Number of studies indicated that the prolonged political instability weakened the country's governance as a critical constraint on private sector investment and development. More recently, the partnerships are being strengthened with the private sector, cooperatives, civil society, development partners and the international community to meet large gaps in national capacity building for sustainable development. Due to limited government resources, there seems more potential for initiating partnerships with the private and international development sectors, which would play a major role in implementing the SDGs in Nepal.

The nation needs a better investment climate, easier administrative processes, liberalized labor laws and improved infrastructure. Ultimately, the binding forces of good corporate governance practices would ensure for efficient, effective and timely attainment of UN-SDGs.

\section{Recommendations for policy and decision implications}

Achieving the SDGs is a big challenge for a country like Nepal that has limited resources, skills and access to technology. Finally, based on above scenario analyses of SDGs and CG, the following recommendations for policy implications have been made:

a. Eradicating poverty and promoting prosperity require coordinated implementation of the SDGs by federal, provincial and local governments. In this respect, the federal government should implement social protection and welfare schemes for poverty reduction, which is possible only by exploiting the external market opportunities for export and the capacity building of industries to produce competitive goods and services. Similarly, provincial governments should create several market zones to support in increasing productivity and building regional capacity of the industry. Whereas, the local governments should have emphasis on development and use of local resources to empower local industry, which in turn, will contribute to trans- 
form overall socio-economic livelihood situation in all local units of the country.

b. Implementation of the SDGs requires stable, participatory, visionary, development-oriented and people-centric federal, provincial and local governments. It means governance should be strong at all levels.

c. There should be a specific provision of additional financing for infrastructure development for promoting agriculture such as improving irrigation, power, rural roads, and ICT infrastructure. In this respect all the federal, provincial and local governments should co-ordinate and collaborate each other and should act with functional responsibility and accountability for the development and commercialization of agriculture sector by providing several development schemes and incentives.

d. Nepal has adopted integrated water resources management as its approach for developing its water resources in its policy and a plan document, but its implementation has remained very poor. And it has been seen that the farmers of Nepal has been successfully managing the water resources. Therefore the local, provincial and federal government should implement on the efforts used by farmers to manage water resources to manage other water resource. The regulatory frameworks should be revised in the light of integrated water resources management. And also the private sectors and non-government organization working for climates and natural resource management should be actively participative and also initiate water management programs up to their possibility.

e. Clean energy management and development has been a very important subject in today's world and as well in Nepal too. For this the government of Nepal has been making many plans from both local and provincial stages, like the local government in Kathmandu has plans and working to make the city clean and green and use less carbon emission. As well as there is lean energy development bank in Nepal to encourage investments in clean energy and provides funds for small and medium hydel power projects. And also the environment concerned organizations are to put extra efforts on developing the clean energy projects and make programs that could save the environment. The global community should partner with the national government to generate clean energy and to make the most efficient use of it through technology transfer and financial investments.

f. The substantial up-scaling of national efforts along with enlarged international technical and financial support are necessary to achieve the goal of making human settlements safe, and making housing, adequate, and affordable through cooperation with several governments. 
g. Conserving and sustainably using the oceans, seas and marine resources for sustainable development is not relevant for Nepal, but the country should promote mountain resources like mountain snows, water, livelihoods, and wildlife at national level. The federal government should make compulsory to the provincial and local government to make programs that would help protect the natural resources and also promote the life of people through sustainable use of the resources.

h. Government should bring certain changes in policies that will promote global trade, investment and labor market opportunities, where advanced and developing partner countries can also facilitate. The trade can be only encouraged and promoted when the local government, provincial and federal government come together as a team to get ultimate trade growth through coordinating trades between each of them and make policies and strategies that can benefit everyone involved in trade.

i. Prioritization needs to be given to those SDGs that have multiplier effects and larger impacts on poor and marginalized people, peasants, children and women at local, provincial and federal level.

j. SDGs being shared responsibility, both the national government and international development partners should be working together to address the resource, governance, and capacity gaps at the country level and as well as possible provincial and local level as well. As it gives the correct information on the gaps, the possible opportunity and the exact data and information on the available resources that can be used and developed to gain SDGs and national strength and improvement in peoples life.

k. SDGs are very much data intensive so far as their monitoring and tracking the progress is concerned. The progress must be tracked at a highly disaggregated level and large numbers of surveys have to be done to meet the data gap. Therefore the government should make records at different levels like local , provincial stages which will give the clear ideas on here and how much the designed SDG programs are working effectively and where should the program be restructured and given focused on.

1. Prioritization of projects and programs should be based on synergy that they can bring in the development process, having larger social impact.

m. A large portion of activities under SDGs are to be held at the private sector and other non-government development actors. All non-government actors including the private sector should be brought under the monitoring purview of the plan and the SDGs. They should be both given leverages on their best performing works and also keep a tight supervision on the misleading work that can hamper in the governance and attainment of SDGs. 


\section{References}

Ali, M. (2015). Governance and good governance: a conceptual perspective. The Dialogue, X(1), 65-77. Available at: http://www.qurtuba.edu.pk/thedialogue/The\%20Dialogue/10_1/Dialogue_January_March2015_65-77.pdf. Retrieved on: January 20, 2019.

Aras, G., \& Crowther, D. (2008). Governance and sustainability: An investigation into the relationship between corporate governance and corporate sustainability. Management Decision, 46(3), 433448. Available at: https://www.emeraldinsight.com/doi/pdf/10.1108/o0251740810863870. Retrieved on: April 20, 2019.

Asogwa, I. E. (2016). Corporate Governance in Nigerian Banks: a Theoretical Review. International Journal of Management Science and Business Administration, 2(7), 7-15. Available at: https://www. researchgate.net/publication/319376896_Corporate_Governance_and_Voluntary_Disclosure_A_Literature_Review. Retrieved on: May 5, 2019.

Dine, J., \& Koutsias, M. (2013). The nature of corporate governance: the significance of national cultural identity. Edward Elgar Publishing. Available at: https://core.ac.uk/download/pdf/16388018.pdf. Retrieved on: January 20, 2019.

Homayoun, S., \& Rahman, R. A. (2010). Determinants of web-based corporate reporting among top public listed companies in Malaysia. International Journal of Arts and Sciences, 3(13), 187-212. Available at: https://pdfs.semanticscholar.org/4108/19cee554ao6of8869dee1247add4fboo264f. pdf. Retrieved on: May 1, 2019.

Janggu, T., Darus, F., Zain, M. M., \& Sawani, Y. (2014). Does good corporate governance lead to better sustainability reporting? An analysis using structural equation modeling. Procedia-Social and Behavioral Sciences, 145, 138-145. Available at: https://www.sciencedirect.com/science/article/pii/ S1877042814038786. Retrieved on: April 24, 2019.

King, M. E. (2002). King Report on Corporate Governance for South Africa-2002: Executive Summary. Institute of Directors in Southern Africa. Printed in the Netherlands. Available at: http://www. ecseonline.com/PDF/King\%20Committee\%20on\%20Corporate\%20Governance\%20-\%20Executive\%20Summary\%20of\%20the\%20King\%20Report\%202002.pdf. Retrieved on: May 10, 2019.

Khan, H. (2011). A literature review of corporate governance. International Proceeding of Economics Development and Research. Singapore: International Association for Computer and Information Science. Available at: https://www.researchgate.net/publication/267773286_A_Literature_Review_of_Corporate_Governance. Retrieved on: January 20, 2019.

Kocmanová, A., Hřebíček, J., \& Dočekalová, M. (2011). Corporate governance and sustainability. Economics and Management, Czech Republic: Brno University of Technology. Available at: https://www.researchgate.net/publication/228461240_CORPORATE_GOVERNANCE_ AND_SUSTAINABILITY. Retrieved on: January 29, 2019.

Ministry of Finance. (2018). Economic survey 2017/18. Kathmandu: Government of Nepal. Available at: https://mof.gov.np/uploads/document/file/for\%20web_Economic\%20Survey\%202075\%20 Full\%20Final\%2ofor\%20WEB\%20_20180914091500.pdf. Retrieved on: February 13, 2019.

National Planning Commission (NPC). (2015). Sustainable

development goals 2016-203o. Kathmandu: Government of Nepal. Available at: http://www.np.undp. org/content/dam/nepal/docs/reports/SDG\%2ofinal\%2oreport nepal.pdf. Retrieved on: January 20, 2019. 
Nestlé. (2018). Nestlé in society creating shared value and meeting our commitments 2017. London: Global Reporting Initiative. Available at: https://www.nestle.com/asset-library/documents/library/ documents/corporate_social_responsibility/nestle-csv-full-report-2017-en.pdf. Retrieved on: May 6, 2019.

Okaro, S. C., Ofoegbu, G. N., \& Okafor, G. O. (2018). Corporate governance and sustainable development in Nigeria: prospects and challenges. International Journal of Academic Research in Business and Social Sciences, 8(9). Available at: https://www.researchgate.net/profile/Grace_ Ofoegbu/publication/328410792_Corporate_Governance_and_Sustainable_Development_ in_Nigeria-Perspectives_and_Challenges/links/5bcbad40458515f7d9ce3057/Corporate-Governance-and-Sustainable-Development-in-Nigeria-Perspectives-and-Challenges.pdf. Retrieved on: May 10, 2019.

Quang, C., Kim, K., \& Yi, Y. (2014). Effects of corporate governance on the performance of private economic groups in Vietnam. Journal of International Trade and Commerce. Available at: https:// mpra.ub.unimuenchen.de/81062/1/MPRA_paper_81062.pdf. Retrieved on: January 20, 2019.

Strange, T., \& Bayley, A. (2008). Sustainable development. Paris: Organization for Economic Co-operation and Development Publishing. Available at: http://www.sjalfbaerni.is/media/frodleikur/ OECD-skyrsla.pdf. Retrieved on: January 25, 2019.

United Nations Organization (UNO). (1986). Our common future. Chapter 2: towards sustainable development. NY: Author. Available at: http://www.un-documents.net/ocf-02.htm. Retrieved on: January 30, 2019. 